\title{
Rigid Spine Syndrome in Children
}

\author{
Roshan Koul ${ }^{1, *}$ \\ ${ }^{1}$ Department of Child Health, Sultan Qaboos University Hospital, College of Medicine and Health Sciences, Muscat, Oman \\ "Corresponding author: Roshan Koul, Department of Child Health, Sultan Qaboos University Hospital, College of Medicine and Health Sciences, Muscat, Oman. Tel: \\ +96-824413128, E-mail: koulroshan@gmail.com, koul@squ.edu.om
}

Received 2015 November 06; Revised 2016 March 16; Accepted 2016 June 06.

\begin{abstract}
Context: Rigid spine syndrome is rare in children. It is commonly observed in the end stage of the muscular dystrophies. Another entity called primary rigid spine or spinal muscular dystrophy syndrome, rigidity of spine is noted at the beginning of a muscle disease. The two conditions should be differentiated.

Evidence Acquisition: The first child with primary rigid spine syndrome was observed in 1996. Twelve children were observed over the last eighteen years and were followed up regularly in the hospital under study. The children were diagnosed with rigid spine syndrome if there was restriction of the neck movements, particularly on the bending of the spine. The diagnosis was based on clinical features, biochemical tests, electrophysiological findings, imaging and muscle biopsy. Genetic tests were not available in the past, but were done recently in three children.

Results: Twelve children (nine males and three females) were observed. Ten children had primary rigid spine and two had secondary rigid spine syndrome.

Conclusions: The current study described twelve children with rigid spine syndrome from Oman; ten with primary rigid spine (rigid spinal muscular dystrophy) and two with secondary rigid spine syndrome. The condition is rare in children. Early neck stiffness is the key to diagnosis.
\end{abstract}

Keywords: Rigid Spine Syndrome, Primary, Children, Magnetic Resonance Imaging, Selenomyopathy

\section{Context}

Rigid spine literally means a stiff spine. The condition is common in old age. Various conditions related to muscles, bones, systemic diseases, drugs or neurological diseases result in rigid spine $(1,2)$. Rigid spine is rare in children and the two most common causes are the primary muscle disease end stage and rigidity at onset of a rare muscle disease called primary rigid spine syndrome. The etiology in the former is related to the underlying primary muscle disease. In the primary rigid spine the disease starts in the paraspinal muscles. This type is missed most of the times. In this disease the parents particularly complain about their child not able to look down while walking. These children do not have any other muscle weakness, other than neck and spine muscles involvement. Over time the weakness spreads to other body muscles, particularly intercostals. This entity is called primary rigid spine or rigid spinal muscular dystrophy (3). In the primary or rigid spinal muscular dystrophy the muscle disease is of nonspecific origin or due to congenital myopathies such as multicore disease, desmin-related myopathy with Mallory body-like inclusions. Here, the disease origin is outside dystrophin, glycoprotein or extracellular matrix (4).
The muscle histopathology in the majority of the cases is nonspecific similar to myopathy changes with fibro fatty accumulation (5). Images of the spine show atrophy of the paraspinal muscles, a diagnostic feature. Recently malfunction of selenoproteins is recognized as the main defect in the muscles of such children. Mutations in selenoprotein $\mathrm{N} 1$ related myopathy gene were associated with this disease and four siblings were mapped to 1p35-36 (6). Another name given to this condition is selenomyopathy (6). What initiates the disease in the paraspinal muscles is unknown. The current report aimed to present this rare entity in children.

\section{Evidence Acquisition}

Twelve children were observed in the last eighteen years and followed up regularly in the hospital under study. The children were diagnosed with rigid spine syndrome if there was restriction of the neck movements, particularly on the bending of the spine. The diagnosis was based on clinical features, biochemical tests, electrophysiological findings, imaging and muscle biopsy. Genetic tests were not available in the past, but were done recently in three children. 


\section{Results}

\subsection{Clinical Features}

These children present with inability to bend the neck and look down on the ground. The examination reveals stiffness of spine and restricted neck movements, particularly flexion. Nine out of the twelve children with rigid spine syndrome were male (75\%). Developmental delay (mainly gross motor) was noted in seven cases and was normal in five. Age of onset ranged from birth to 18 months with a mean of eight months and five days. Age at presentation was from two years to 12 years. The family history was positive in two cases; one subject had an affected sister while a family had three affected children, (two boys and one girl). The children with primary rigid spine syndrome had spine and neck muscle involvement and rest of the neurological examinations were normal at the beginning of the illness. The neck muscles particularly extensors and sternomastoids were thin and wasted. The neck appeared very thin on examination. Rotation, extension and flexion movements were severely affected in all cases. Rest spine was bent and difficult to extend fully. The Gower sign was negative in all cases. They could not bend the neck (Figures 1 and 2). The children with rigid spine syndrome as part of primary muscle disease had typical features of the underlying disease with positive Gower sign. Serum creatine kinase was normal in all cases with primary rigid spine syndrome but was elevated in the two cases with the secondary rigid spine syndrome. Electromyography (EMG) was myopathic; nerve conductions and brain magnetic resonance imaging (MRI) were normal in all cases. Spine MRI revealed typical features (loss of muscle mass in the paraspinal muscles, hypointensity and fatty infiltration) in primary rigid spine syndrome and the features were normal in the subjects with rigid spine (Figures 3 and 4). Muscle biopsy was done in five children. Three subjects with primary rigid spine syndrome had nonspecific myopathy; in two subjects there were mild variation in fiber size, fatty infiltration, no necrosis or regeneration changes, no lymphocytic infiltrations and normal immune histochemistry; and one showed multicore type of congenital myopathy by the electron microscopy investigation (Figure 4); while one girl with rigid spine syndrome had mitochondrial cytopathy, another one had nonspecific congenital myopathy. Selenoprotein N1 deletion was negative in one boy and positive in another one with the primary rigid spine syndrome (Table 1).

\subsection{Differential Diagnosis}

Clinical features help to differentiate the two types of rigid spine syndrome. Primary disease features dominate the secondary rigid spine syndrome. However some of

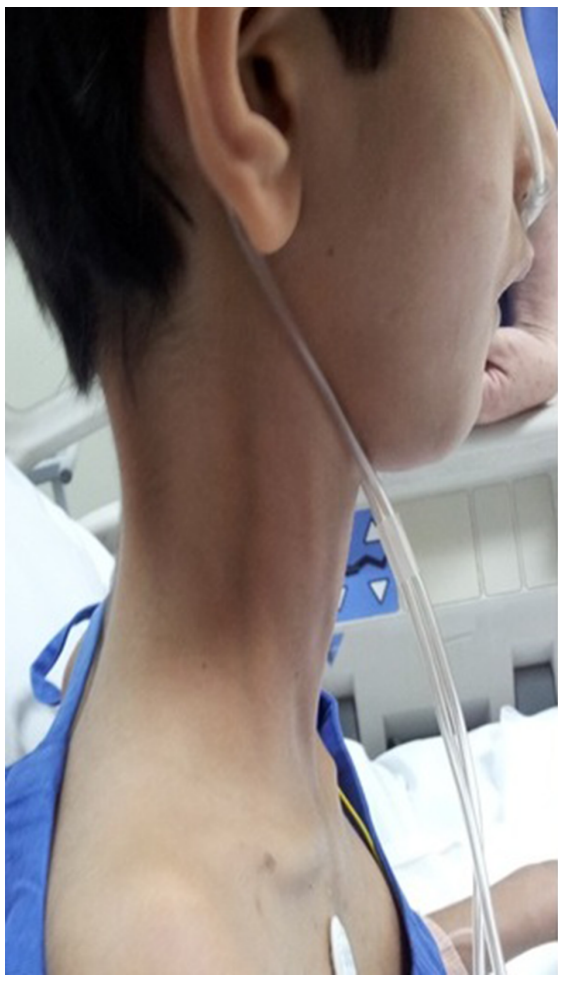

Figure 1. A Boy With Primary Rigid Spine Syndrome not Able to Bend his Neck (With Permission From SQUMJ 2015; 15:364-369)

the clinical features may resemble X-linked Emery- Dreifuss muscular dystrophy (7). In Emery- Dreifuss muscular dystrophy, there is wasting in proximal upper limbs muscle along with contractures and early cardiac involvement. The serum creatine kinase is high, electrocardiography (ECG) is abnormal and muscle biopsy and genetic testing confirm the diagnosis. Dystonia may sometimes be confused with neck stiffness. Sometimes such children label as stiff-person syndrome. Generalized body stiffness involvement, even abdominal muscles, is observed in the stiff-person syndrome. One of the study subjects was diagnosed with stiff-person syndrome abroad.

\subsection{Management}

The treatment is symptomatic. Physiotherapy and occupational therapy are the main forms of treatment in such children. There is early involvement of the respiratory muscles in primary rigid spine syndrome. Respiratory care and using bi-level positive airway pressure (BIPAP) to are labeled reduce pulmonary dysfunction, prolong the life expectancy in such children.

Currently, no drug treatment is available. Based on the pathophysiology of selenoprotein N1, it plays a role in pro- 
Table 1. Information About the Children With Primary Rigid Spine and Rigid Spine Syndrome

\begin{tabular}{|c|c|c|c|c|c|c|c|c|}
\hline Disease Type & $\begin{array}{l}\text { Age at Onset of } \\
\text { Disease, } M\end{array}$ & Development & $\begin{array}{c}\text { Age at } \\
\text { Presentation, } Y\end{array}$ & $\begin{array}{l}\text { Creatine Kinase } \\
\text { Level, IU/L }\end{array}$ & EMG & ECG & Muscle Biopsy & $\begin{array}{l}\text { Imaging Spine, } \\
\text { MRI }\end{array}$ \\
\hline Primary & 6 & $\mathrm{~N}$ & 12 & 94 & Myo & $\mathrm{N}$ & Myo+fat+collagen & $\begin{array}{l}\text { Muscle wasting, } \\
\text { hypointensity, } \\
\text { fibro fatty } \\
\text { infiltration }\end{array}$ \\
\hline Primary & 6 & $\mathrm{~N}$ & Not seen & Not done & Not done & & Not done & Not done \\
\hline Primary & Unknown & $\mathrm{N}$ & 7 & 150 & Myo & $\mathrm{N}$ & No & $\begin{array}{l}\text { Muscle wasting, } \\
\text { hypointensity, } \\
\text { fibro fatty } \\
\text { infiltration }\end{array}$ \\
\hline Primary & 18 & $\mathrm{~N}$ & 5 & 145 & Myo & $\mathrm{N}$ & No & $\begin{array}{l}\text { Muscle wasting, } \\
\text { hypointensity, } \\
\text { fibro fatty } \\
\text { infiltration }\end{array}$ \\
\hline Primary & 8 & $\mathrm{~N}$ & 5 & 151 & Myo & $\mathrm{N}$ & Not agreed & $\begin{array}{l}\text { Muscle wasting, } \\
\text { hypointensity, } \\
\text { fibro fatty } \\
\text { infiltration }\end{array}$ \\
\hline Secondary + & 10 & Motor delay & 2 & 856 & Myo & $\mathrm{N}$ & $\begin{array}{l}\text { Mitochondria } \\
\text { changes in shape } \\
\text { and size }\end{array}$ & Normal \\
\hline Primary* & 5 & Motor delay & 6 & 147 & Myo & $\mathrm{N}$ & $\begin{array}{l}\text { Nonspecific } \\
\text { myopathy }\end{array}$ & $\begin{array}{l}\text { Muscle wasting, } \\
\text { hypointensity, } \\
\text { fibro fatty } \\
\text { infiltration }\end{array}$ \\
\hline Primary & 12 & Motor delay & 11 & 200 & Myo & $\mathrm{N}$ & Not agreed & $\begin{array}{l}\text { Muscle wasting, } \\
\text { hypointensity, } \\
\text { fibro fatty } \\
\text { infiltration }\end{array}$ \\
\hline Primary & 15 & Motor delay & 9 & 187 & Myo & $\mathrm{N}$ & Not agreed & $\begin{array}{l}\text { Muscle wasting, } \\
\text { hypointensity, } \\
\text { fibro fatty } \\
\text { infiltration }\end{array}$ \\
\hline Primary & 15 & Motor delay & 8 & 230 & Myo & $\mathrm{N}$ & Not agreed & $\begin{array}{l}\text { Muscle wasting, } \\
\text { hypointensity, } \\
\text { fibro fatty } \\
\text { infiltration }\end{array}$ \\
\hline Primary + & 6 & Motor delay & 10.4 & 123 & Myo & $\mathrm{N}$ & Multicore disease & Not done \\
\hline Secondary & At birth & Motor delay & 5.6 & 800 & Myo & $\mathrm{N}$ & $\begin{array}{l}\text { Congenital } \\
\text { myopathy of } \\
\text { uncertain type }\end{array}$ & Not done \\
\hline
\end{tabular}

tection of human cell against oxidative stress (8). Antioxidants could help to prevent such effects in ex vivo (8). Surgical resection of cervical muscles and bone grafts were done in the past as part of the management in such children (9).

\subsection{Prognosis}

The disease spreads slowly to other muscles of the body. Intercostal muscles are affected earlier than the limb muscles. Respiratory failure is observed earlier in the primary rigid spine syndrome. Respiratory support, BIPAP ventilation is required in the terminal stages of the disease.

\section{Conclusions}

Adults with rigid spine have a bent spine (forward) with often a drooping head. The children have upright head, and the neck is so stiff that the patient cannot look at the ground. Primary rigid spine disease is of nonspecific origin or observed in congenital myopathies such as multicore disease, desmin-related myopathy with Mallory body-like inclusions. The disease origin is outside dystrophin, glycoprotein or extracellular matrix. The muscle histopathology is nonspecific similar to myopathy changes with fibro fatty accumulation $(6,10)$. Imaging of the spine is diagnostic in this condition. It shows atrophy of the paraspinal muscles (Figure 3). Recently, it was found 


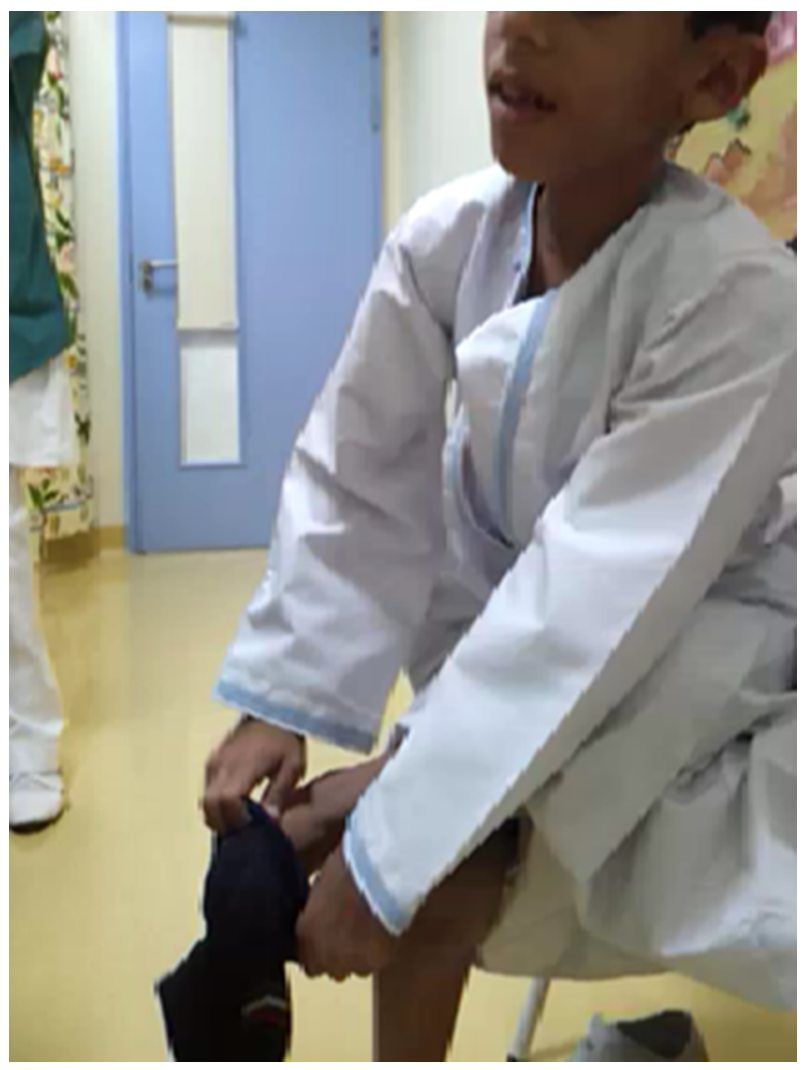

$\overline{\text { Figure 2. A Boy Trying to Put on Socks but Could not Bend his Neck to Look at the Act }}$

that mutations in selenoprotein $\mathrm{N} 1$ related myopathy gene were associated with this disease. There is involvement of selenocysteine in primary rigid spinal muscular dystrophy. Four siblings were mapped to 1p35-36 in rigid spinal muscular dystrophy $(4,11)$. Rigid spine syndrome and primary rigid spine syndrome should be differentiated from the adult onset rigid spine. The adult onset rigid spine is uncommon in children. In adult onset there is bent spine and bent neck while in primary rigid spine syndrome and rigid spine of children there is rigidity of spine with inability to flex the neck.

The underlying etiology differs in adults from children. The causes vary from those of bone, neuromuscular and brain diseases. It presents from the $4^{\text {th }}$ to $6^{\text {th }}$ decade of life in adults (12-14) and the first decade of life in children $(15,16)$. Several names are given to the stiff spine in adults like axial myopathy, camptocormia and recently para spinal neuromuscular syndrome $(13,14)$. Axial myopathy in adults has many similar features to primary rigid spine syndrome in children (12). Six (two males and four females) patients with this entity and the age range of 49-72 years were reported. A detailed clinical, histopathological,

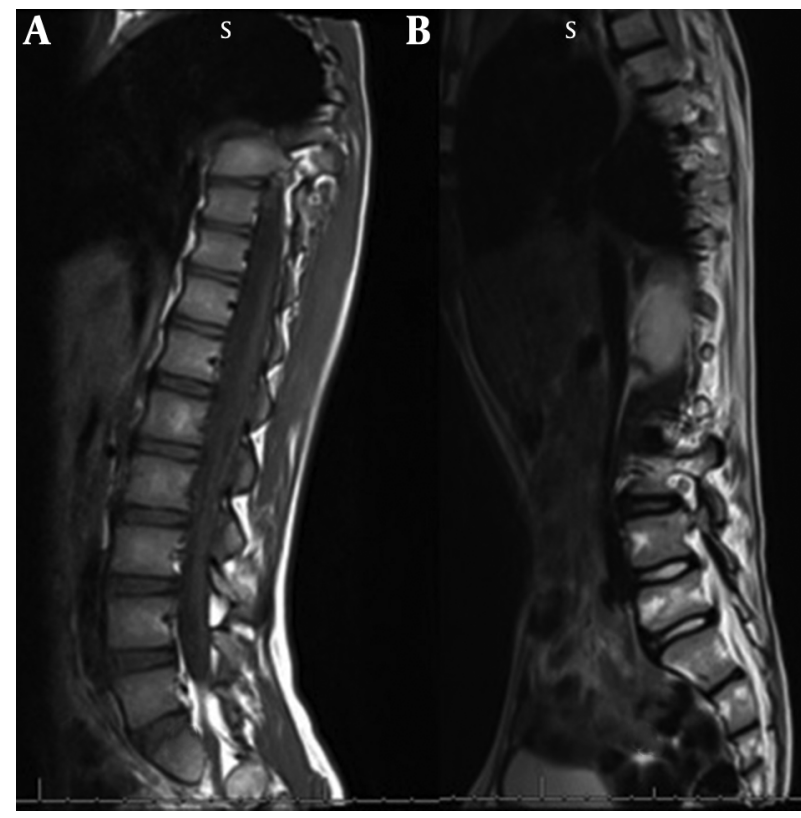

Figure 3. Comparison between normal back muscle bulk (left A) and wasted muscle in the primary rigid spine syndrome (right B).

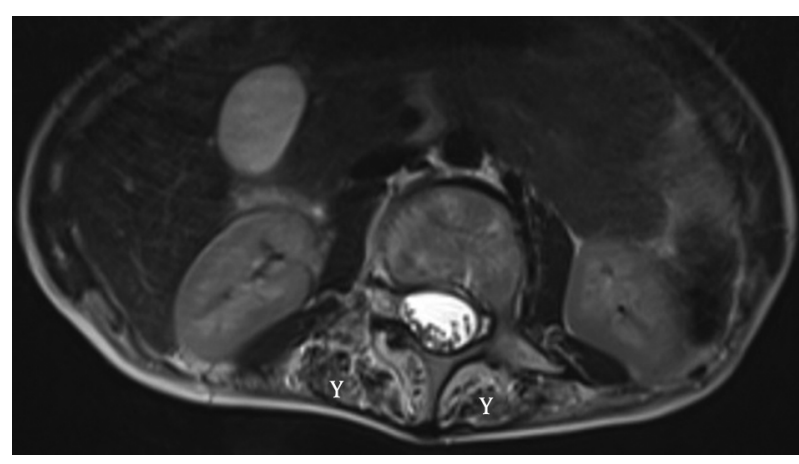

Figure 4. Axial MRI Spine Shows Wasting and Fat Replacement of the Back Muscles of the Spine (With Permission from SQUMJ 2015; 15:364-369)

MRI, molecular genetics and electrophysiological investigations were carried out in the patients. The disease was slowly progressive. There was marked thoracic kyphosis with dropped head in all subjects. Weakness and wasting of spinal muscles was noted in all subjects. MRI revealed selective involvement of interspinalis, intercostalis and multifidis muscles. The upper and lower limb muscles were normal. Three out of six patients had elevated creatine kinase, two to five times more than normal. Spinal muscle biopsy was carried out in the six patients. There was disorganization of the normal architecture, variation in fiber size, marked fibrosis and replacement by adipose tissue. 


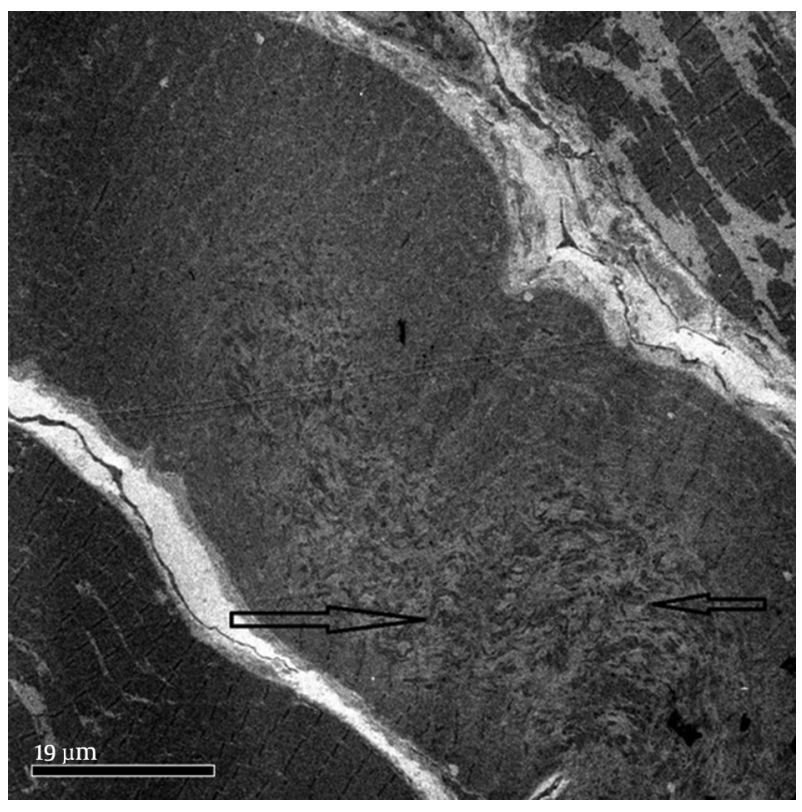

Figure 5. Muscle Histopathology (Electron Microscopy) Shows Mallory Bodies (With Permission From SQUMJ 2015; 15:364-369)

There was no necrosis or regeneration. No or scant lymphocytic infiltration was observed. .Immunohistochemistry was normal. It was concluded that a rare entity of axial myopathy had no known cause and required a detailed work up to exclude other conditions in old age. Sixteen adults with the onset mean age of $51.5 \pm 19.9$ years were evaluated for camptocormia in Parkinson and dystonia center (14). Eleven had Parkinson disease and four had dystonia. Twelve had minimal or no improvement on levodopa and nine received botulinum toxin type A (Botox) into rectus abdominus muscle with improvement in four. It was concluded that camptocormia was a heterogeneous disorder with multiple etiologies and variable responses to the systemic and local therapies. In a recent review article, the phenotype of dropped head and bent spine syndrome was labelled as paraspinal neuromuscular syndromes (13). This condition may be caused by many underlying etiologies. The majority of the isolated cases were paraspinal myopathy. The etiology should be clarified in every single case to treat the underlying cause correctly.

Secondary rigid spine is noted in late stages of several childhood muscle dystrophies and myopathies, mainly congenital myopathies. In these children, the rigidity of spine is due to the spread of the disease to paraspinal muscles at the end stage of the myopathy. Elevated creatine kinase, late involvement of respiratory muscles and normal MRI of paraspinal muscles are observed in them. Muscle biopsy and genetic tests confirm the diagnosis. However the disease course is reverse in primary rigid spine syndrome. It seems to be a genetically programmed entity, with the disease onset in the paraspinal muscles. Serum creatine kinase and echocardiography are normal. There is no proximal weakness at the onset of the disease and the diagnosis is made by the features of spine stiffness and MRI showing loss of muscle mass in the paraspinal muscles particularly erector spinae $(10,15)$. Mutations in selenoprotein N1 gene were associated with primary rigid spinal muscular dystrophy. It was tested in two of the patients. It was positive in one and negative in another subject. The treatment remains mainly physiotherapy, though surgical intervention and use of BIPAP to reduce pulmonary dysfunction have prolonged the life expectancy in them.

This review described twelve children with rigid spine syndrome from Oman. Ten had primary rigid spine (rigid spinal muscular dystrophy) and two had secondary rigid spine syndrome. The condition is rare in children. A regional genetic factor may be involved in geographical distribution. Early neck stiffness is the key to diagnosis.

\section{Acknowledgments}

Author is greatly indebted to the children and their parents for permission to take photographs. Sincere thanks to the Sultan Qaboos university hospital (college of Medicine and Health Sciences, Muscat, Oman) for allowing this work to be published in various journals.

\section{Footnotes}

Authors' Contribution: Roshan Koul, senior consultant child neurology at Sultan Qaboos university hospital, prepared the manuscript.

Financial Disclosure: The current study received no funding or financial support.

\section{References}

1. Lenoir T, Guedj N, Boulu P, Guigui P, Benoist M. Camptocormia: the bent spine syndrome, an update. Eur Spine J. 2010;19(8):1229-37. doi: 10.1007/s00586-010-1370-5. [PubMed: 20300781].

2. Serratrice G. Axial myopathies: an elderly disorder. Acta Myol. 2007;26(1):11-3. [PubMed: 17915564].

3. Dubowitz V. 50th ENMC International Workshop: congenital muscular dystrophy. 28 February 1997 to 2 March 1997, Naarden, The Netherlands. Neuromuscular disorders: NMD. 1997;7(8):539-47.

4. Flanigan KM, Kerr L, Bromberg MB, Leonard C, Tsuruda J, Zhang P, et al. Congenital muscular dystrophy with rigid spine syndrome: a clinical, pathological, radiological, and genetic study. Ann Neurol. 2000;47(2):152-61.

5. Reed UC. Congenital muscular dystrophy. Part I: a review of phenotypical and diagnostic aspects. Arq Neuropsiquiatr. 2009;67(1):144-68. [PubMed: 19330236]. 
6. Schara U, Kress W, Bonnemann CG, Breitbach-Faller N, Korenke CG, Schreiber G, et al. The phenotype and long-term follow-up in 11 patients with juvenile selenoprotein N1-related myopathy. Eur J Paediatr Neurol. 2008;12(3):224-30. doi: 10.1016/j.ejpn.2007.08.011. [PubMed: 17951086].

7. Swaiman KF, Ashwal S, Ferriero DM, Schor NF. Swaiman's pediatric neurology: Principles and practice. 5th ed. Philadelphia, PA: Elsevier, Saunders; 2012. pp. 1570-606.

8. Arbogast S, Beuvin M, Fraysse B, Zhou H, Muntoni F, Ferreiro A. Oxidative stress in SEPN1-related myopathy: from pathophysiology to treatment. Ann Neurol. 2009;65(6):677-86. doi: 10.1002/ana.21644. [PubMed: 19557870].

9. Giannini S, Ceccarelli F, Granata C, Capelli T, Merlini L. Surgical correction of cervical hyperextension in rigid spine syndrome. Neuropediatrics. 1988;19(2):105-8. doi: 10.1055/s-2008-1052411. [PubMed: 3374763].

10. Isozaki E, Fujimoto Y, Kawata A, Matsubara S, Hirai S. [Clinical and myopathological studies on rigid spine syndrome]. Rinsho Shinkeigaku. 1996;36(10):1136-42. [PubMed: 8997137].

11. Sponholz S, von der Hagen M, Hahn G, Seifert J, Richard P, Stoltenburg-
Didinger G, et al. Selenoprotein N muscular dystrophy: differential diagnosis for early-onset limited mobility of the spine. J Child Neurol. 2006;21(4):316-20. [PubMed:16900928].

12. Mahjneh I, Marconi G, Paetau A, Saarinen A, Salmi T, Somer H. Axial myopathy-an unrecognised entity. J Neurol. 2002;249(6):730-4. doi: 10.1007/s00415-002-0701-9. [PubMed: 12111307].

13. Clovstok T, Hirano M. Clinical summary: Paraspinal neuromuscular syndromes [March 2015]. Available from: http://www.medlink.com/ cip.asp".

14. Azher SN, Jankovic J. Camptocormia: pathogenesis, classification, and response to therapy. Neurology. 2005;65(3):355-9. doi: 10.1212/01.wnl.0000171857.09079.9f. [PubMed: 16087897].

15. Koul R, Al-Yarubi S, Al-Kindy H, Al-Futaisi A, Al-Thihli K, Chacko $\mathrm{PA}$, et al. Rigid spinal muscular dystrophy and rigid spine syndrome: report of 7 children. J Child Neurol. 2014;29(11):1436-40. doi: 10.1177/0883073813479173. [PubMed: 23481446].

16. Koul R, Sankhla D, Al-Jahdhami S, Mani R, Rahim RA, Al-Yaarubi S, et al Rigid Spine Syndrome among Children in Oman. Sultan Qaboos Univ Med J. 2015;15(3):364-9. doi: 10.18295/squmj.2015.15.03.010. [PubMed: 26357557]. 